\title{
Analysis of Ecological Condition of Taiga Topsoil During Commercial Development
}

\author{
Yuriy Sivkov ${ }^{1}$, Artur Nikiforov ${ }^{1 *}$ \\ 1 Department of Technospheric Safety, Tyumen Industrial University, Tyumen, Russia \\ * Corresponding author's e-mail: arhont607@gmail.com
}

\begin{abstract}
The paper analyses the ecological properties of taiga topsoil during its commercial development and assesses the consequences of impact which will be made by the future facilities on the environment (taking into account the types of impact, their characteristics, the tendencies of transformation in the nature systems growing with the increase of service life, which were detected at the producing fields), sanitary and socioeconomic aspects of the facilities operation under the conditions of specific geographical complexes. The object of study included waspodzolic and swamp-podzolic soils located in the Uvat district in Khanty-Mansiysk Autonomous Region of Tyumen region, in the area of potential impact of industrial facilities. The method of study implied the selection of soil specimens and their examination according to the standard practices. Ten specimens were taken from each of three areas of sampling. The specimens were subjected to office study in order to determine eleven parameters. The sources of impact made by the oil and gas facility on the environment were the material objects (buildings, constructions etc.), elements and assemblies of basic and auxiliary technologies which result in pollutants emission. The major impact on topsoil at the stage of preparatory works and construction of facilities was the mechanical damage to the natural state of soils. It is primarily connected with sites stripping from forestry and ground leveling. The paper reviews the issues of ecological condition of topsoil and forecast of possible changes while commercial development of the studied area. A negative load on soil may be decreased through planning and implementation of organizational measures on assessment of current state of the topsoil within the field and environmental threat from basic and auxiliary industrial facilities.
\end{abstract}

Keywords: soil, pollutants, oil, industrial development, ecology.

\section{INTRODUCTION}

The development of oil fields generates a strong man-caused burden on the environment, which - in some cases - leads to a complete destruction of natural complexes [Podavalov 2010]. Increasing the area of man-made landscapes causes a diversified negative impact not only immediately within the developing fields, but far beyond their borders too [Golovanov 2009]. The environmental pollution with oil causes relevant responses in all components of ecosystems, including soil [Petrov et al. 2016]. When oil and oil products infiltrate into the soil, deep and often irreversible changes occur in the morphological, physical, physicochemical and other properties, and sometimes the entire soil pro- file restructures significantly [Salanginas 2003, Faboya et al. 2016].

Oil is a complex pollutant and its impact on soils and other landscape components is determined with the amount, composition and properties of both organic and inorganic compounds [Goldberg et al. 2001]. In its composition, oil bears the signs which indicate its relation to the hydrothermal ore-forming solutions. Such signs include, for example, the presence of numerous metals and other elements such as $\mathrm{S}, \mathrm{O}, \mathrm{P}, \mathrm{V}, \mathrm{K}$, $\mathrm{Na}, \mathrm{Ni}, \mathrm{Si}, \mathrm{Ca}, \mathrm{Fe}, \mathrm{Mg}, \mathrm{Al}, \mathrm{Mn}, \mathrm{Pb}, \mathrm{Ag}, \mathrm{Au}, \mathrm{Cu}$, Ti, U, Su, As in oil [Obiajunwa et al. 2002]. In the overwhelming majority of oil fields, waters in the oil-bearing beds are highly mineralized; they may be salty water (from 10 to $50 \mathrm{~g} / \mathrm{l}$ ) or brine (over $100 \mathrm{~g} / \mathrm{l}$ ). 
According to the contemporary vision, oil consists of low- and high-molecular hydrocarbon and non-hydrocarbon components. It is a dispersed system characterized with complex internal arrangement which can change with the impact of external factors. Oil is a liquid natural solution consisting of a plenty of hydrocarbons of various composition and high-molecular asphaltenic substances [Liao et al. 2015]. It contains some amount of dissolved water, as well as salts of trace elements. Oil from various fields may be characterized, on the one hand, by a great variety of its types, and on the other hand, uniformity of its composition and structure. The elemental composition of tens of thousands various individual kinds of oil all over the world varies within 3-4\% per each element. Major oil-forming elements are: carbon (83-87\%), hydrogen (12-14\%), nitrogen, sulfur, oxygen $(1-2 \%$, rarely $3-6 \%$ at the expense of sulfur). Oil also contains numerous trace elements in the amount of tenths and second decimals of a percent, and the list of such elements is mostly the same [Kireeva et al. 2008].

In general, the pollutants are mechanically washed out and migrate to the adjacent territories [Piekutin 2015] during oxidative degradation of oil in the soil. Therefore, a study of ecological condition of soil adjacent to the oil-production areas is of topical importance [Sivkov et al. 2016].

The objects of study are podzolic and swamp-podzolic soils located in the Uvat district in Khanty-Mansiysk Autonomous Region of Tyumen region, in the area of potential impact of industrial facilities.

The purpose of study is to examine the ecological properties of taiga topsoil during the development of oil fields.

The study was performed in order to assess the contemporary state and forecast possible changes in the environment caused with man-made load in order to prevent and minimize the hazardous and adverse ecological consequences and the related social, economic and other effects and to preserve optimal conditions of living for the population.

\section{MATERIALS AND METHODS}

The climate of the studied territory is stipulated with its geographical location and, thus, low insolation. Important factors affecting the climate formation on this territory are westward air-mass transport and its continentality. The interaction of these factors ensures a quick interchange of cyclones and anti-cyclones which contributes to a quick change of weather and strong winds. Flattened relief does not ensure sufficient runoff flow, thus creating the conditions for superfluous moisture of underlying terrain and the air. The climate formation is affected with long-term soil freezing, plenty of swamps, lakes and rivers.

The studied region is characterized with cold and long winter with strong winds and snowstorms, relatively short warm summer as well as short springs and autumns.

In accordance with the soil-geographical regionalization of Tyumen region, the studied territory refers to the subzone of podzolic andswamppodzolic soils in taiga zone.

Depending on the lithological and orographic conditions, two groups of soils which differ with moisture regime [Mamontov et al. 2017] exist:

- territories of loamy water partings where the seasonally frozen horizons, which thaw for a long time (until the mid-July/August), slow down the vertical drain of moisture and cause the seasonal water logging and gleyzation of all soil profile;

- sandy and sandy-loam terraces above floodplain and slope loamy drained surfaces of terraces, which are characterized with quick thawing of the frozen horizons, formation of sustainable flushing regime and localization of gleyzation signs in the deep horizons.

The lack of warmth and long-lasting frozen condition reduces the active period of soil formation, thus slowing down the processes of biochemical transformations, and stipulating the possibility of intensive peat accumulation on the soil surface.

On the basis of the resistance to mechanical impact on the studied territory, several categories of soil may be identified.

Slow resistance is specific to topsoil in inundable landscapes like turf gley and alluvial turf soils.

Moderate resistance is specific to flat slightlydrained surfaces of loamy and sandy-loam water partings covered with dark coniferous-birch and pine-dark coniferous sphagnous forests on turfpodzolic-alluvial-gley soils and bog landscapes in topographic lows with turf and turf-gley soils.

Drained peak plains of sandy-loam water partings, smooth loamy slopes of river valleys and plains covered with dark coniferous forests are relatively resistant. They consist mostly of various podzolic-alluvial-gley soils. 
Within the framework of study, taiga soils from Uvat district in Tyumen region were sampled and analyzed.

The list of chemical elements and compounds identified in the soils was selected as required with SanRaR (Sanitary Rules and Regulations) 2.1.7.1287-03 "Sanitary and Epidemiological Requirements to the Soil Quality" [SanRaR 2003].

The soil condition was analyzed according to the following criteria: oil products, phenols, chlorides, mercury, copper (acid-soluble form), lead (acid-soluble form), total ferrum, zinc (acid-soluble form), nickel (acid-soluble form), cadmium (active form), manganese.

The level of topsoil pollution is assessed through the comparison of pollutant content in the specimens to maximum permissible concentration (MPC) and approximate permissible concentration (APC) of chemical compounds in soils taking into account their background content.

\section{DISCUSSION}

The studied territory is currently characterized with local man-made changes in the natural environment. The period of man-made transformation of the district territory is estimated as 45-50 years; moreover, the major impact has occurred over the last 10-15 years. The basic works conducted on the territory include seismic prospecting and exploratory drilling.
In general, the area of man-made land changes across the studied territory currently totals 15.7 thousand hectares.

The studied territory refers to the areas with moderate man-made changes which do not exceed $5-7 \%$ of the general area of changes.

Ten specimens were sampled from each of three areas (S1, S2, S3). The specimens were subject to office study in order to determine eleven parameters. Findings of the laboratory examinations of substances are represented in the Table 1.

The oil product content is minimal in the $\mathrm{S} 3$ specimen and amounts to $142.75 \mathrm{mg} / \mathrm{kg}$ and maximal $-219.62 \mathrm{mg} / \mathrm{kg}$ in the S2 specimen. In accordance with the Yu.I.Pikunovsky's scale of oil product rating [Pikovsky 2016] (Table 2), this level of soil pollution with oil products may be characterized as increased in relation to the background.

In terms of the phenols content, the largest concentration is registered in the S1 specimen $-1.45 \mathrm{mg} / \mathrm{kg}$, and the smallest in the $\mathrm{S} 2$ specimen $(0.15 \mathrm{mg} / \mathrm{kg})$, which is stipulated with remoteness from the sources of impact. The chloride concentration in the soils across the studied territory is equal in all specimens and below 0.5 $\mathrm{mg} / \mathrm{l}$. The mercury content in the soil specimens is not significant and lower than $0.025 \mathrm{mg} / \mathrm{kg}$ (below 0.01 of MPC).

The content of pollutants in the soil specimens in comparison to MPC is represented on the Figure 1. The maximal concentration of zinc (acid-soluble form) in soils is revealed in the $\mathrm{S} 1$ specimen $-13.50 \mathrm{mg} / \mathrm{kg}$ ( 0.58 of MPC). The nick-

Table 1. Results of laboratory studies on substances

\begin{tabular}{|l|c|c|c|c|c|}
\hline \multicolumn{1}{|c|}{$\begin{array}{c}\text { Name of the determined } \\
\text { indicator }\end{array}$} & \multirow{2}{*}{$\begin{array}{c}\text { Unit. } \\
\text { measurements }\end{array}$} & \multirow{2}{*}{ MPC (APC) } & \multicolumn{3}{c|}{ Indicator value } \\
\cline { 4 - 6 } & & $\mathrm{S} 1$ & $\mathrm{~S} 2$ & $\mathrm{~S} 3$ \\
\hline Petroleum products & \multirow{2}{*}{$\mathrm{mg} / \mathrm{kg}$} & - & 162.00 & 219.62 & 142.75 \\
\cline { 4 - 6 } Phenols & & 1.0 & 1.45 & 0.15 & 0.36 \\
\hline Chlorides & $\mathrm{mg} / \mathrm{kg}$ & - & $<0.5$ & $<0.5$ & $<0.5$ \\
\hline Mercury & $\mathrm{mg} / \mathrm{kg}$ & 2.1 & $<0.025$ & $<0.025$ & $<0.025$ \\
\hline
\end{tabular}

Table 2. Scale of rationing of petroleum products by Yu.I. Pikovsky

\begin{tabular}{|l|l|l|}
\hline \multicolumn{2}{|c|}{ Concentration. $\mathrm{mg} / \mathrm{kg}$} & \multicolumn{1}{c|}{ Assessment of contamination } \\
\hline Up to 100 & Background content: environmental hazards do not represent \\
\hline \multirow{3}{*}{$100-500$} & $\begin{array}{l}\text { The content is elevated relative to the background: oil products in such quantities are } \\
\text { actively utilized by microorganisms or washed out by rain streams without human } \\
\text { intervention }\end{array}$ \\
\hline \multirow{3}{*}{ More than 500} & $500-1000$ & Moderately polluted \\
\cline { 2 - 3 } & $1000-2000$ & Moderately hazardous pollution \\
\cline { 2 - 3 } & $2000-5000$ & Highly hazardous pollution \\
\hline Over 5000 & Very strong pollution. subject to sanation \\
\hline
\end{tabular}


el content (acid-soluble form) within the studied territory is the highest in the S3 specimen (7.75 $\mathrm{mg} / \mathrm{kg}$ ), which makes 0.09 of MPC, and in other specimens $-6.75 \mathrm{mg} / \mathrm{kg}(0.07$ of MPC). The cadmium content in all specimens is practically the same and totals $0.08-0.09 \mathrm{mg} / \mathrm{kg}$ (0.04 MPC). Manganese concentration within the studied territory varies from $54.75 \mathrm{mg} / \mathrm{kg}$ (S3) to $73.00 \mathrm{mg} / \mathrm{kg}$ (S1) (not more than 0.05 of MPC). Copper in the specimens complied with the values from 9.00 to $9.50 \mathrm{mg} / \mathrm{kg}(0.16-0.17$ of MPC). The lead content ranged from 3.00 to $4.50 \mathrm{mg} / \mathrm{kg}$ which complies to 0.10 and 0.15 of MPC. The iron content in the specimens was the highest $(2513 \mathrm{mg} / \mathrm{kg})$ in the $\mathrm{S} 3$ specimen (12.56 of MPC), $4000 \mathrm{mg} / \mathrm{kg}$ in the $\mathrm{S} 1$ specimen (20.00 of MPC) and $4800 \mathrm{mg} / \mathrm{kg}$ in the S2 specimen (24.00 of MPC), which is indicative of possible pollution with formation waters.

For the purposes of comprehensive characteristics of the soil condition, the value of aggregate soil pollution $\left(\mathrm{Z}_{\mathrm{C}}\right)$ was calculated according to the formula below (1):
Copper

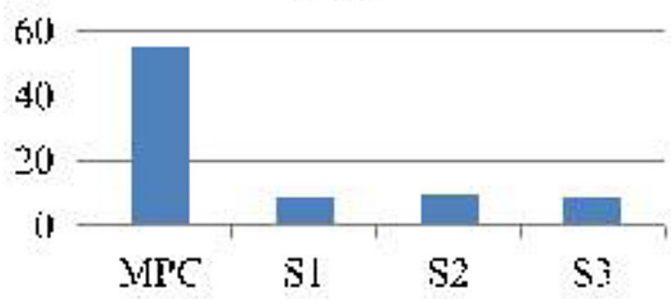

Iron

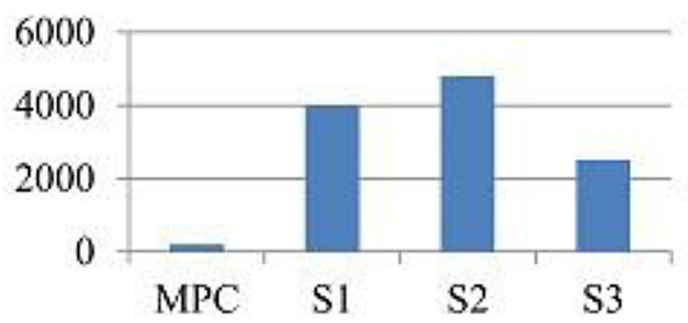

Cadmium

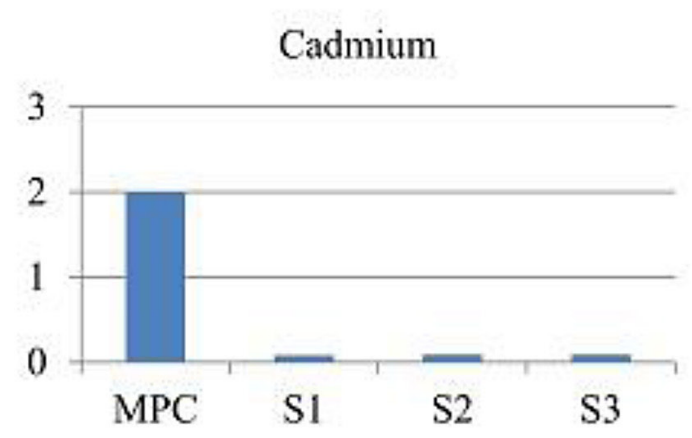

Lead

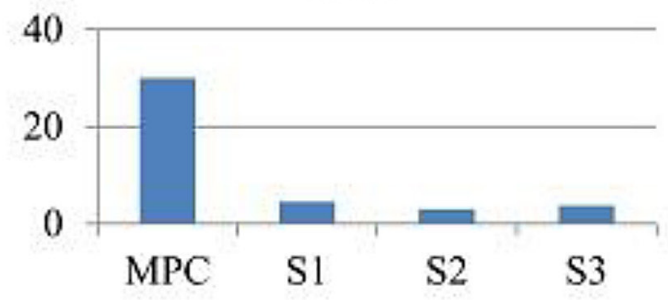

Zinc:

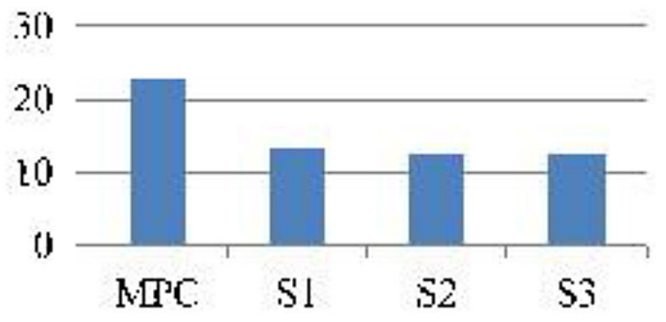

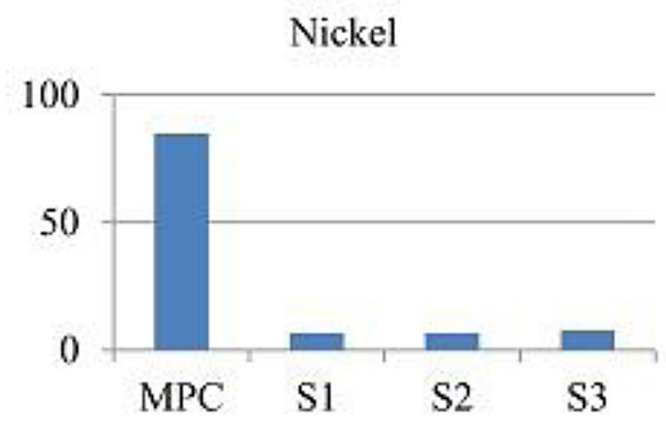

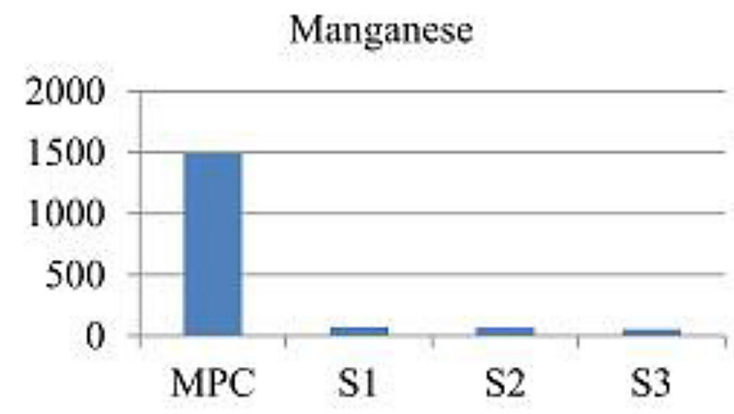

Figure 1. Content of pollutants in the soil specimens, $\mathrm{mg} / \mathrm{kg}$ 


$$
\mathrm{Z}_{\mathrm{C}}=\left(\sum_{\mathrm{i}=1}^{\mathrm{n}} \frac{\mathrm{C}_{\mathrm{i}}}{\mathrm{C}_{\mathrm{i} \Phi}}\right)-(\mathrm{n}-1)
$$

where $C_{i}$ - is the actual content of pollutant in the soil;

$C_{i \phi}$-is the background content of pollutant in the soil or its maximum allowable concentration;

$n$ - is the number of abnormal (concentration exceeds the background content or MAC) substances.

The results of calculations are displayed graphically on the Figure 2.

The analysis of the Figure 2 may lead to the conclusion that in accordance with the reference scale of soil pollution hazard based on the value of aggregate soil pollution (table 3) [Guidelines 1999], soil in S3 area is rated as "passable". The soil in S1 and S2 areas is characterized as "moderately hazardous". These characteristics of soil in the areas are mostly stipulated with high concentrations of phenol and iron.
During the study, special attention was also paid to the assessment of the impact which will be made by the future facilities on the environment (taking into account the types of impact, their characteristics, the tendencies of transformation in the nature systems growing with increase of service life, which were detected at the producing fields), the sanitary and socioeconomic aspects of the facilities operation under the conditions of specific geographical complexes, land and water ecosystems.

The sources of impact made by the oil and gas facility on the environment will include the material objects (buildings, constructions etc.), elements and assemblies of basic and auxiliary technologies which result in pollutants emission. The impact on the environment will be determined through the withdrawal of land, water, mineral and agricultural resources, flora and fauna habitats (including the reproduction and migration places) from the environment; introduction of pollutants, noise and warmth; complex processes of biogeochemical metabolism in geotechnical systems.

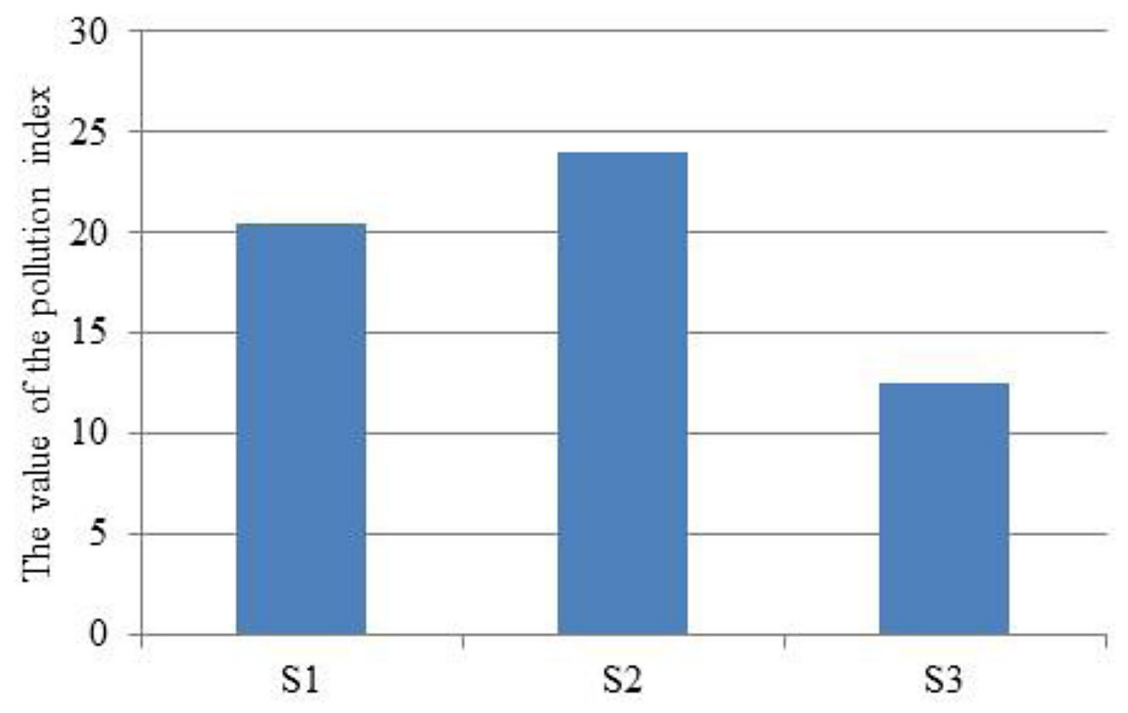

Figure 2. The value of aggregate soil pollution on the reference areas

Table 3. Approximate estimated scale of danger of soil contamination by the total pollution index (Zc)

\begin{tabular}{|l|l|l|}
\hline $\begin{array}{c}\text { Categories of soil } \\
\text { contamination }\end{array}$ & \multicolumn{1}{|c|}{ The quantity $Z_{c}$} & \multicolumn{1}{c|}{ Changes in health indicators of the population in foci of contamination } \\
\hline Permissible & Less than 16 & $\begin{array}{l}\text { The lowest incidence of children and the minimum incidence of functional } \\
\text { abnormalities }\end{array}$ \\
\hline $\begin{array}{l}\text { Moderately } \\
\text { hazardous }\end{array}$ & $16-32$ & Increase in total morbidity \\
\hline Hazardous & $32-128$ & $\begin{array}{l}\text { An increase in the overall incidence. the number of often ill children. children with } \\
\text { chronic diseases. disorders of the functional cardiovascular system }\end{array}$ \\
\hline Extremely dangerous & More than 128 & $\begin{array}{l}\text { An increase in the incidence of the child population. a violation of the } \\
\text { reproductive function of women (an increase in the toxicosis of pregnancy. the } \\
\text { number of premature births. stillbirth. hypotrophy of newborns) }\end{array}$ \\
\hline
\end{tabular}


The major impact on topsoil at the stage of preparatory works and construction of facilities will be the mechanical damage of natural state of soils. It is primarily connected with the sites stripping from forestry and ground leveling. The types of impact based on the extent of topsoil damage are displayed in Figure 3.

Preparation of sites for multiple well platforms or construction of industrial, auxiliary and supporting facilities changes the intended use of land and leads to its alienation due to placement of process and production facilities [Melnikov 2009].

The conducted analysis of topsoil condition and forecast of possible consequences of impact which will be made by the future facilities on the environment allows for defining the topsoil protection measures.

Minimal area of soil damage during construction of the production facilities may be ensured through:

- the system of corridor line utilities;

- construction of the areal facilities during the winter time;

- conductance of construction works and transport traffic strictly within the right-of-way of the land;

- drilling of wells with diagonal and horizontal method on the existing or new multiple well platforms in order to reduce the area of lands designated for pad;

- application of drilling technique that requires no water storage.

In order to minimize the negative impact on topsoil during the service period, the following measures should be taken:
- automotive transport and special vehicles must move only along the traffic roads;

- reinforcement of slopes of the line structures and sites with turf-sand mixture and sowing of grass in order to prevent from water and wind erosion;

- separated collection and storage of waste in special containers or tanks for further transportation to the special landfills or processing.

A major impact on soils during preparation and construction of the facilities on oil field manifests itself through the mechanical damage of topsoil within the land allocation. In this regard, the top-priority task of soil protection entails prevention of the mechanical damage. The measures of reducing the negative impact on soils include:

- conductance of construction works on the soils which are more resistant to the mechanical damage;

- avoidance of any topsoil damage not envisaged with the project beyond the borders of the developed territories, gas pipelines, utility lines;

- the facilities construction should be carried out on fill-up ground protecting the natural soils from deformation and impact of vehicles;

- arrangement of runoff in order to prevent water pocketing on the surface of backfill and peripherally;

- arrangement of surface water drainage away from the sites;

- construction of a concrete wall around the tank battery and a concrete ground on the fuel and lubricant storage;

- installation of special pallets and other assemblable units in the places of possible leaks and spillage of fuel and lubricants, drilling and other fluids.

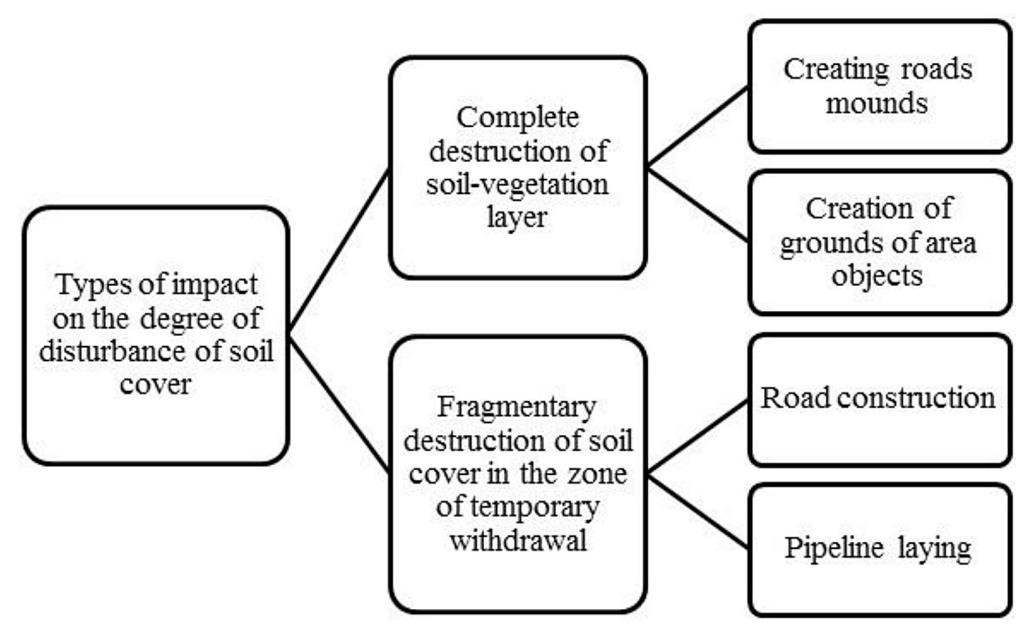

Figure 3. Types of impact on the degree of disturbance of soil cover 


\section{CONCLUSION}

The article studied the ecological properties of taiga soils in the Uvat district in order to examine the contemporary condition and to forecast possible adverse consequences during further commercial development.

The studied territory refers to the areas with moderate man-made changes which do not exceed $5-7 \%$ of the general area of changes.

Ten specimens were taken from each of three areas of sampling. The specimens were subjected to office study in order to determine eleven parameters.

The analysis of the obtained results may lead to the conclusion that, in accordance with the reference scale of soil pollution hazard based on the value of aggregate soil pollution, the soil in S3 area is rated as "passable", and the soil in S1 and $\mathrm{S} 2$ areas is characterized as "moderately hazardous". These characteristics of soil in the areas are mostly stipulated with high concentrations of phenol and iron.

During the study, special attention was also paid to the assessment of the impact which will be made by the future facilities on the environment (taking into account the types of impact, their characteristics, the tendencies of transformation in the nature systems growing with increase of service life, which were detected at the producing fields), sanitary and socioeconomic aspects of the facilities operation under the conditions of specific geographical complexes, land and water ecosystems.

A more detailed study of impact made by the designed facilities on the environment may be carried out upon the introduction of the monitoring system, i.e. control over the changes in the environment components during the facility construction and operation.

\section{REFERENCES}

1. Faboya O.L., Sojinu S.O., Sonibare O.O., Falodun O.T., Liao Z. 2016. Aliphatic biomarkers distribution in crude oil-impacted soils: an environmental pollution indicator. Environmental Forensics. 1, 27-35.

2. Goldberg V.M., Zverev V.P., Arbuzov A.I. et al. 2001. Technogenic pollution of natural waters by hydrocarbons and its ecological consequences. Monograph Moskow. 125.
3. Golovanov A.I. 2009. Disturbed soils recultivation: textbook Moscow. 325.

4. Guidelines 2.1.7.730-99. "Hygienic assessment of soil quality in populated areas".

5. Kireeva N.A., Bakaeva M.D., Galimzyanova N.F. 2008. Evaluation of the effect of various methods of oil-polluted soil bioremediation on micromycete complexes. Applied Biochemistry and Microbiology. 1, 55-59.

6. Liao C., Xu W., Lu G., Liang X., Guo C., Yang C., Dang Z. 2015. Accumulation of hydrocarbons by maize (ZEA MAYS L.) in remediation of soils contaminated with crude oil. International Journal of Phytoremediation. 7, 693-700.

7. Mamontov V.G., Panov N.P., Ignatiev N.N. 2017. General pedology: Textbook Moscow. 538.

8. Melnikov A.A. 2009. Environmental problems and the strategy of its conservation: Proc. Manual for universities Moscow. 720.

9. Obiajunwa E.I., Pelemo D.A., Owolabi S.A., Fasasi M.K., Johnson-Fatokun F.O. 2002. Characterisation of heavy metal pollutants of soils and sediments around a crude-oil production terminal using EDXRF. Nuclear Instruments and Methods in Physics Research Section B: Beam Interactions with Materials and Atoms. 1, 61-64.

10. Petrov A.M., Versioning A.A., Karimullin L.K., Akaikin D.V., Tarasov O.Y. 2016. Dynamics of ecological and biological characteristics of soddypodzolic soils under long-term oil pollution. Eurasian Soil Science. 7, 784-791.

11. Piekutin J. 2015. Evaluation of petroleum hydrocarbons elution from soil. Journal of Ecological Engineering. 16(3), 14-19.

12. Pikovsky Yu. I. 2016. Natural and technogenic flows of hydrocarbons in the environment. Monograph Moskow. 206.

13. Podavalov Y.A. 2010. Oil and Gas Production Ecology: textbook Moscow. 416.

14. Salanginas L.A. 2003. Change in the properties of soils under the influence of oil and the development of a system of measures for their rehabilitation. Monograph Ekaterinburg. 411.

15. SanRaR (Sanitary Rules and Regulations) 2.1.7.1287-03 "Sanitary and Epidemiological Requirements to the Soil Quality".

16. Sivkov Y.V.,Parfenov V.G,Aleksandrov S.V., Nikiforov A.S. 2016. Research of the ecological state of soils in oil producing areas of Western Siberia. $16^{\text {th }}$ International Multidisciplinary Scientific GeoConference. Ecology, Economics, Education and Legislation. 2(5), 665-672. 